\title{
Educação e espiritualidade como experiencias fundamentais para humanização em Paulo Freire
}

\author{
Adilson Castro Chaves - Faculdade Joaquim Nabuco. \\ Ricardo Pereira Silva - Faculdade Joaquim Nabuco. \\ Clemildo Anacleto da Silva - Centro Universitário Metodista - IPA. \\ Emanoel Rodrigues de Almeida -Universidade Estadual do Ceará.
}

\section{RESUMO}

Esta pesquisa bibliográfica tem o objetivo de contribuir com os estudos relacionados a temática da educação e espiritualidade. Embora pareça existir uma tensão antagônica entre a educação e espiritualidade, a mesma se dá pelo entendimento do que significa a espiritualidade. Aqui, pretenderemos analisá-la do ponto de vista da categoria pedagógica capaz de contribuir no desenvolvimento do homem no sentido de torná-lo capaz de situar-se no mundo como agente ativo, consciente da realidade opressora que lhe envolve. $\mathrm{O}$ referencial teórico que fundamenta a ideia é a pedagogia de Paulo Freire. Entendemos que em sua pedagogia, além dos traços teóricos do marxismo, é possível identificar traços de um modelo de espiritualidade, não alienante, que não romantiza o cotidiano opressor do homem, mas que lhe permite situar-se no mundo de forma consciente e humanizador.

\section{PALAVRA-CHAVE}

Educação, espiritualidade, liberdade, conscientização e humanização. 


\section{ABSTRACT}

This bibliographical research aims to contribute to the studies related the theme of education and spirituality. Although, it may seem there is an antagonistic strain between education and spirituality, the same occurs, by understanding what it means to spirituality. Here will analyze the same point of view as pedagogical category able to contribute to the development of man in order to make it able to be in the world as an active, conscious of the oppressive reality that it involves. In this sense, the theoretical framework on which the idea is the pedagogy of Paulo Freire. We understand that in their pedagogy, in addition to the theoretical pulls Marxism, it is possible to identify traces of a model of spirituality, not alienating that romanticizes the everyday oppressor, but allowing you to be in the world of conscious and coherent way, postures that end up his life to humanize.

\section{KEYWORDS}

Education, spirituality, freedom, awareness and humanization 


\section{INTRODUÇÃO}

Educação e espiritualidade podem ser consideradas parceiras no processo de formação do homem de modo que lhe permita desenvolver a capacidade de desvelar as contradições e desafios do mundo que lhe cerca? Em primeira mão a proposta pode soar antagônica, pois a pedagogia tradicional insere a educação no campo da ciência e a espiritualidade no campo da fé, do irracional. Entretanto, mais do que nunca a ciência tradicional tem entendido que conceituar o homem puramente como um ser mecânico racional, movido apenas pela ciência, entre todas, também a educação como meio evolutivo do homem, não respondeu todas as angustias do homem "civilizado".

Na tentativa de ocupar esta lacuna existencial humana o tema da espiritualidade vem ganhando visibilidade em todo cenário mundial. A derrocada do discurso de evolução social tecno-racionalista não conseguiu imprimir o desenvolvendo prometido capaz de solucionar os problemas clássicos referente ao relacionamentos humano. A urbanização, por exemplo, junto a estética da cidade acentuou ainda mais a violência, ausência de tempo para cultivo de relacionamentos sólidos, tempo de descanso, a vida humana tornou-se escrava do trabalho que promete poder de consumo-ter-ostentar.

O caminho proposto por esse estilo de vida desestabiliza as principais esferas emocionais humanas desordenando o sentido da vida, neste sentido, a espiritualidade, não como uma forma doutrinaria denominacional, mas como força que devolve o sentido da vida pode se colocar como categoria pedagógica do processo humanizador do homem. O referencial teórico que baseia essa forma de cultivar a espiritualidade como caminho da humanização será analisada a partir da Pedagogia de Paulo Freire. Entendemos que em sua Pedagogia ele aponta os traços fundamentais de uma espiritualidade libertadora que se coloca como categoria pedagógica que leva em consideração a integralidade humana.

Isto posto, este trabalho tem como objetivo geral demonstrar a relação entre educação e espiritualidade articulada pela pedagogia paulofreiriana.

Este texto é de caráter qualitativo do tipo bibliográfico. A primeira parte irá se ocupar de demonstrar
Paulo Freire como um educador de fé. A segunda, trata dos pilares da pedagogia paulofreiriana. A última trata da educação e da espiritualidade como experiências fundantes no processo de humanização

\section{PAULO FREIRE, UM EDUCADOR DE FÉ}

Em sua última entrevista, gravada em vídeo pela (TVPUC-SP, 1997), poucos dias antes de sua morte, Paulo Freire se autodefine como um homem de fé, um cristão convicto. Diz ele, "eu me sinto entre os que: creem na transcendental idade; segundo, eu me situo entre aqueles que, crendo na transcendental idade, não dicotomizam a transcendentalidade da mundanidade". Já no final da entrevista, conclui Paulo Freire, "eu fiquei com Marx na mundanidade, a procura de Cristo na transcendentalidade".

De acordo com a afirmação de Freire não é preciso dicotomizar educação e religião. Assim Marx ajudou Paulo Freire a perceber, a ver melhor, a contradição da sociedade injusta, inclusive da escola, e ao seu redor. E que, este ver melhor já é um passo para a superação da realidade de poucos que "são" e de muitos impossibilitados de ser, e que, assim, passo a passo, buscamos a transcendência (SANTIAGO, JUNQUEIRA, 2002). Assim é possível iluminar nossa imanência através da educação para que saibamos buscar a nossa transcendentalidade, nossa capacidade de perceber-se capaz de desenvolver-se espiritualmente, através da educação que conscientiza para humanizar.

Entretanto, como não poderia ser, a espiritualidade que fundamenta a pedagogia de Paulo Freire de maneira nenhuma é concebida pela ideia de ópio, que aliena e romantiza o homem frente as injustiças sociais do cotidiano, mas, pelo contrário, nas palavras de Queiroz (2013), ele é apresentado da seguinte maneira:

Um modelo de espiritualidade que tem como práxis fundamental a crítica de todo o sistema opressor que em nome de uma suposta divindade oprime o povo como vontade-opressão do desejo dessa divindade. Esse modelo crítico de espiritualidade segue na contramão de um modelo de espiritualidade fertilizada pela magia e fetichismo, espiritualidade que fundamento o mercado religioso profundamente antiético que supervaloriza o estético em detrimento do ético. 
Desta forma, como homem e educador de fé, Paulo Freire desenvolve uma pedagogia profundamente fundamentada em um modelo de espiritualidade descrita, por exemplo, pelo texto base do XI Encontro Intereclesial das Comunidades Eclesiais de Base no Brasil, como:

Uma espiritualidade libertadora, pois, é uma forma de encarar a realidade conflitiva que deve ser transformadora na casa comum de todos os seres humanos em paz com a natureza. Já o Vaticano II nos indica esta articulação: A fé, com efeito, esclarece todas as coisas com luz nova. Manifesta o plano divino sobre a vocação integral do ser humano. $\mathrm{E}$ por isso, orienta a mente para soluções plenamente humanas" (CEBs, 2004).

Concebida desta maneira, a Pedagogia de Paulo Freire lança mão da espiritualidade com características libertadoras quando se coloca como categoria pedagógica capaz de educar para liberdade, através da humanização que valoriza a justiça, a liberdade e a esperança, mesmo diante das contradições da condição existencial humana. É possível compreender esta máxima a partir da análise do pensamento de Freire.

\section{PILARES DA PEDAGOGIA PAULO FREIRENA: CONSCIENTIZAÇÃO, LIBERDADE E HUMANIZAÇÃO}

\subsection{Conscientização}

Apesar do vocábulo "conscientização" estar frequentemente associado ao "método de alfabetização" de Paulo Freire, e ter sido mundialmente difundido por suas obras, não é ele o autor desse vocábulo. A expressão é resultado de uma reflexão conjunta dos professores do Instituto Superior de Estudos do Brasil (ISEB), por volta do ano de 1964. Em seu sentido original, conscientização implicava ação, isto é, uma relação particular entre o pensar e o atuar (OLIVEIRA \& CARVALHO, 2007). Relação particular, pois a natureza do atuar corresponde à natureza da compreensão. Se a compreensão é ingênua, a ação também será. Se for crítica, assim será a ação (FREIRE, 2006). Somente a este último se refere o sentido original da conscientização.
Para Paulo Freire, esse sentido original se mantém. Em sua compreensão, a conscientização consiste no desenvolvimento crítico da tomada de consciência. É o processo de superação da esfera espontânea de apreensão da realidade (consciência ingênua), alcançando uma esfera crítica na qual a realidade se dá como objeto cognoscível e na qual o homem assume uma posição epistemológica, consciência crítica (FREIRE, 2001), que corresponde ao desejo de compreender e apoderar-se da realidade que o circunda, atuando na sua transformação. Por isso, "a realidade não pode ser modificada, senão quando o homem descobre que é modificável e que ele pode fazê-lo" (FREIRE, 2001). Essa descoberta de que a realidade é modificável e que o homem pode modificá-la caracteriza o processo de conscientização.

É importante observar que, sendo fiel ao sentido original da palavra conscientização, Paulo Freire reconhece que a conscientização não existe sem a práxis, sem o ato ação-reflexão. O ato ação-reflexão é a unidade dialética central que movimenta o processo de conscientização (FREIRE, 2001), baseando-se na concepção dialética que Paulo Freire apresenta da consciência humana, vista. Uma pessoa "em conscientização" é aquela "em descobrimento" da razão de ser das coisas, atuando sobre elas de forma transformadora, aprofundando ainda mais essa descoberta.

A realidade humana não pode ser encarada de forma determinada, feita, imutável, mas algo em constante construção em que o homem, através de sua práxis, interage de maneira determinante. A conscientização é o início da evolução crítica da tomada de consciência em um primeiro momento, desvelando a realidade, e culmina na práxis, ação e reflexão, em um segundo momento, avançando na evolução crítica da tomada de consciência, de forma permanente. Portanto, procurar desvelar a realidade adotando uma postura frente à realidade, sem se engajar, sem interagir e sem transformar a realidade, em uma posição que Paulo Freire acusa como falsamente intelectual, a isso não podemos chamar de conscientização (FREIRE, 2001). "Ao oprimido não basta saber-se oprimido; mas a conscientização deve inseri-lo em um processo de transformação da realidade" (OLIVEIRA \& CARVALHO, 2007). 
No mundo em que vivemos, se verdadeira, a conscientização leva o homem a um estado de perturbação conduzindo-o à ação, o transcende, palavra clássica do campo da espiritualidade. Isto acontece porque ao compreender a sua responsabilidade na transformação ou manutenção da realidade em que a grande maioria dos homens e mulheres padecem de fome, de sofrimento, de falta de amor e cuidado, ele se envolve e transforma a realidade opressora. $\mathrm{O}$ que antes não era percebido em suas implicações mais profundas assume agora o caráter de problemas e desafios (FREIRE, 2005).

Finalmente, por essa inserção no processo de transformação é que a conscientização é um compromisso histórico de libertação, permitindo que os homens assumam o papel de sujeitos que fazem e refazem o mundo, construindo sua história. E por ser um compromisso histórico, o processo de conscientização não terminará nunca, sob pena de se criar novos mitos e novas ilusões imutáveis. "Ao extirpar os mitos e conhecer a realidade, o homem cria uma nova consciência. Ao transformar o mundo, se constrói como novo homem, que recria uma nova história" (OLIVEIRA \& CARVALHO, 2007).

\subsection{Liberdade}

A tese central da obra de Freire é a liberdade-libertação. Segundo Gadotti (1996) "a liberdade é o ponto central de sua concepção educativa desde suas primeiras obras. A libertação é o fim da educação. A finalidade da educação é libertar-se da realidade opressora e da injustiça; tarefa permanente e infindável". Em suas primeiras obras, a liberdade tem uma conotação sociológica, é das condições injustas, desequilibradas, desumanas da realidade social que Freire procura desvelar, desvencilhar-se. No fim de sua vida, em sua última obra, Pedagogia da Autonomia, Freire (1996) principaliza uma conotação ontológica da liberdade, evidenciando a autonomia como liberdade e independência moral do sujeito, em que este possui a possibilidade de escoIher as leis que regem sua conduta. A educação exerce, aqui, o papel de viabilização dessa autonomia, dessa liberdade do sujeito.

O tema da liberdade passa por uma transição entre o início e fim da obra de Freire, de uma posição sociológica para uma ontológica; mas, mesmo quando considerada ontologicamente, ele nunca distanciou-se da questão sociológica da liberdade. A relação de sua obra com a situação opressora também passa por uma transição: de uma opressão escancarada, óbvia, discrepante entre uma elite dominadora, usurpadora do conforto e bem-estar, sobre uma massa dominada de analfabetos, para uma opressão velada, silenciosa e invisível sobre os sujeitos numa sociedade globalizada. Por isso, uma maior ênfase e preocupação com a liberdade sociológica na primeira, e uma liberdade ontológica na última (BACH \& STOLTZ, 2003).

O papel da educação, para Freire, é fazer do ser humano um sujeito e não um objeto. A inconsciência das forças opressoras da realidade social coisificam o homem, alienam-no dos caminhos de transformação de sua situação, deixam-no numa situação passiva de simples aceitação. O ser humano ajustado tornou-se um objeto da educação, pois sacrificou sua capacidade criadora; na sua passividade, ele está oprimido, descaracterizado, domesticado, descriticizado. Enquanto que o ser humano sujeito, em sua decisão de recriação, escolhe processos de conscientização, ele está com o mundo e não no mundo; sua inserção reside em processos de integração, no lugar de processos de adaptação, acomodação ou ajustamento. O ser humano sujeito é um ser datado e situado, em vez de simplesmente ignorado numa massificação amorfa e destemporalizada (BACH \& STOLTZ, 2003).

Numa análise sucinta, na formulação do conceito de liberdade em Freire estão os ideais de conscientização, humanização, diálogo, comprometimento, responsabilidade, de ser sujeito inacabado, aberto, de decisão e recriação, de ser consequente, crítico, de estar com o mundo, de ser ativo, integrativo, reflexivo, autônomo, situado e datado; enquanto que na relação oposta à liberdade, de opressão, estão os conceitos de domesticação, alienação, massificação, de ser objeto, inconsequente ou coisificado, de fanatismo, sectarização, desumanização, de ser heterônomo, minimizado e cerceado, de estar no mundo, de adaptação, acomodação e ajustamento (BACH \& STOLTZ, 2003). 


\subsection{Humanização}

$\mathrm{Na}$ busca de apresentar o conceito de humanização presente nos escritos de Paulo Freire, Mendonça considera que este recebeu influência de três vertentes do humanismo: o humanismo existencialista, o humanismo cristão e o humanismo marxista (MENDONÇA, 2008). Na perspectiva do humanismo existencialista, Mendonça entende que "Freire considera a ideia de que o ser humano é um ser no mundo, que a sua existência social passa a ser reconhecida a partir do momento em que ele capta pela sua consciência crítica a própria realidade" (MENDONÇA, 2008). Nesse sentido, Freire afirma que ao contrário dos animais que são "seres em si mesmos", os seres humanos são "seres para si". E que são desumanizados quando submetidos a processos que os tornem em "seres para o outro" (FREIRE, 1969).

Freire aponta como características principais da existência humana, sua condição de inacabamento e a capacidade que tem de reconhecer e transformar essa condição, através do processo educativo:

Na verdade, diferentemente dos outros animais, que são apenas inacabados, mas não são históricos, os homens se sabem inacabados. Têm a consciência de sua inconclusão. Aí se encontram as raízes da educação mesma, como manifestação exclusivamente humana. Isto é, na inconclusão dos homens e na consciência que dela têm (FREIRE, 2005).

Dessa forma, demonstra-se que a influência do humanismo existencialista fez como que Paulo Freire afirmasse que o educando não deve ser visto apenas como objeto do processo educativo, mas também como sujeito (PEÑALONZO, 1996). Entretanto, na perspectiva do humanismo cristão, para Mendonça (2008), Freire incorpora a categoria da utopia. Segundo ele, Freire entende a utopia como o realizável, aquilo que pode se concretizar. Para ele, utopia implica denúncia da desumanização e anúncio da humanização, constituindo-se, portanto em uma forma de práxis. Uma práxis caracterizada por uma dimensão profética. Nota-se a presença da espitualidade, pois é onde se insere a prática do profetismo. Essa ideia de utopia não pode ser compre- endida sem o sentido da esperança, como condição da busca humana devido à sua condição de inacabamento (MENDONÇA, 2008).

Gadotti entende, a partir da análise profunda da obra freireana, que se a educação visa a libertação, esta deve estar fundada sobre uma visão utópica, tanto da sociedade quanto do próprio papel da educação:

\begin{abstract}
A educação deve permitir uma leitura crítica do mundo. O mundo que nos rodeia é um mundo inacabado e isso implica a denúncia da realidade opressiva, da realidade injusta, inacabada, e, consequentemente, a crítica transformadora, portanto, o anúncio de outra realidade. $\mathrm{O}$ anúncio é a necessidade de criar uma nova realidade. Essa nova realidade é a utopia do educador (GADDOTI, 1996).
\end{abstract}

Portanto, partindo da compreensão do ser humano como um ser inacabado, um ser em processo constante de autoconstrução e que se faz presente no mundo, Freire entende que, reconhecendo a presença histórica da desumanização é possível humanizar-se. Assim, ele entende que a vocação do ser humano é a busca de sua própria humanização: a busca do "ser mais", isto é: "o objetivo básico de sua busca, que é o ser mais, a humanização, apresenta-se-lhe como um imperativo que deve ser existencializado", através da educação" (FREIRE, 1969).

O tripé, conscientização, liberdade e humanização apresenta a proposta de educação libertadora desenvolvida por Freire que intencionalmente pretende desvelar a realidade desumanizadora que o homem está envolvido. Soares (2008) sintetiza a questão afirmando que "a conscientização acerca das estruturas da dominação tem como objetivo o "engajamento necessário na luta pela liberdade, aspirando a humanização tanto de opressores quanto de oprimidos, pois a desumanização atinge ambos. Embora, o processo pareça ser mecânico, Parker (2001) diz que a força da pedagogia de Freire provinha não apenas de seu conjunto teórico ou da eficácia de sua metodologia, mas da corporificação do amor em seus ensinamentos e em sua pessoa. A corporificação do amor em seus ensinamentos é a expressão radical da espiritualidade em sua pedagogia. 


\section{EDUCAÇÃO E ESPIRITUALIDADE COMO EXPERIÊNCIAS FUNDANTES NO PROCESSO DE HUMANIZAÇÃO}

A maior parte das pessoas pensam que espiritualidade tem a ver com uma consciência ampliada ou aquisição de algum conhecimento esotérico, reservado a poucos, que permitiria conhecer as realidades 'metafisicas' do mundo espiritual, realidades que iriam além do mundo meramente material (SUNG، 2007) entretanto, a espiritualidade se inscreve no plano das motivações mais profundas pelas quais o ser humano vive e orienta sua vida. Boff (2001) define a espiritualidade afirmando que "ela é aquilo que produz em nós uma mudança interior capaz de mudar tudo que está envolvido no campo exterior".

Essa definição coloca a espiritualidade como uma força profunda que move o homem a tomada de consciência do seu lugar no mundo, desvela a realidade e o impulsiona a reagir transformando a sua realidade opressora. Assim, a pedagogia Paulo freireana e sua ideia libertadora, pode ser entendida como processo de humanização que promove libertação pela conscientização.

Neste sentido, para Soares (2008), a espiritualidade ganha fundamental importância para educação libertadora, na medida em que ela é a força misteriosa capaz de sustentar o compromisso com a transformação da realidade opressora. Quando se afirma que a espiritualidade inclui a dimensão do conhecimento é preciso reconhecer a suficiência da conscientização como instrumento da educação para a liberdade que valoriza a vocação ontológica implícita na condição de existir do homem, ou seja, sua vocação para liberdade, através do processo da humanização.

Uma vez que a vocação humana de ser mais se constitui como vocação para a liberdade e que esta é um apelo de ordem espiritual, temos a possibilidade de corresponder a exigência posta pela conscientização, isto é, morrer para nascer de novo como "homem libertando-se", pressupõe a existência de uma dimensão mais profunda que permeie este processo, experiência de natureza espiritual que nos remete a 'religiosidade' presente em todas as pessoas, como desejo de um sentido ultimo da vida que encante e faça valer a pena a existência (SUNG, 2006).
É justamente nesta dimensão que a espiritualidade se inscreve no plano da significação da existência humana. No mais, trata-se de uma experiência de abertura que nos remete a gratuidade das relações onde o outro é reconhecido e aceito como outro em sua humanidade (SOARES, 2008). No entanto, de acordo com Boff (1995) o testemunho daqueles que caminharam exemplarmente, nem sempre nos coloca diante de fórmulas às quais simplesmente se deva seguir, pois para o mundo das pessoas não vigora nenhuma fórmula feita. Descrevendo este fato, Boff afirma:

Cada qual vê o mundo com o olho que possui e sintetiza a realidade a partir de um centro pessoal irredatível. Mesmo que alguém se proponha seguir fielmente os passos, por exemplo, de Jesus Cristo ou São Francisco jamais acabará sendo um ou outro. Terá seguido e construído o seu caminho, na inspiração daquelas mestres. Em outros termos: nunca haverá um simples uso de um caminho feito por outros. Não existem caminhos construídos para o homem que o levem infalivelmente à meta. Ele tem de caminhar. (BOFF,1995)

Seguindo a mesma linha de raciocínio de Boff (1995), Soares (2008) afirma que:

Caminhar pressupõe uma direção, pois a vida contem apelos que nos guiam ora por caminhos que nos levam ao outro, ora por caminhos que nos fecham em nós mesmos. Assim, temos que na dinâmica da natureza mimeticamente desejante do ser humano se inscreve a possibilidade de escolher ou modelos que nos levem a realizar nossa humanidade, isto é, a nos realizarmos como seres de relação que somos, ou modelos que nos conduzem à dominação e à opressão. Os modelos que nos remetem a humanização constituem-se como modelos a partir de sua existência de abertura que brota de sua espiritualidade. É esta experiência de abertura que apreendemos daquelas pessoas que nos convocam e invocam a partir de seu testemunho de vida a caminhar em busca de um sentido que faça valer a pena nossa vida.

A partir destas reflexões é possível dizer que na pedagogia libertadora de Paulo Freire há algo que ele aponta, mas não aprofunda. Algo que se inscreve no fato de que o campo de "atuação" da educação pa- 
ra a liberdade é a vontade humana. Desta forma, a conscientização, instrumento por excelência da educação para a liberdade, não se faz suficiente porquanto ela não é capaz de mudar a direção do desejo humano, via única pela qual é possível mudar o agir humano. Isto porque a força que incide sob o desejo humano e o faz mudar de direção é uma de ordem espiritual. De que modo esta força pode atuar na educação para liberdade que humaniza? (SOARES, 2008).

A partir do testemunho daqueles que nos inspiram e se fazem verdadeiros mestres que nos evocam e convocam. Se inscreve uma dialogicidade que se manifesta em atos de amor, humildade e fé no ser humano, os quais comunicam sua experiência. Experiência de abertura que se revela em sua busca por coerência, em sua práxis, em reconhecimento de si mesmo como seres em processo, como homens e mulheres novos, porque homens e mulheres libertando-se, através da manifestação da espiritualidade libertadora se humanizam. (SOARES, 2008).

Está é uma experiência de abertura. A radicalidade é a qualidade daquele homem novo que se sabe não homem liberto, mas homem libertando-se. E porque se reconhece como ser em processo sabe que a utopia é apenas uma meta longínqua cujo único objetivo é nos impedir de ceder ao imobilismo, é nos fazer caminhar. É a experiência profunda de descobrir a si mesmo no outro esfarrapado que nos leva apenas a compadecer-nos de seu sofrimento, mas a lutar com ele pela libertação. É a experiência de ver, no rosto dos esmagados pela opressão, vítimas injustamente condenadas diante das quais temos que reconhecer nossa própria responsabilidade. (SOARES, 2008).

O reconhecimento de nossa própria responsabilidade indica que começamos a trilhar a caminhada da vida sob o ponto de vista da coerência. Desta forma, a ética supera o projeto estético de uma sociedade tão superficial como está que vivemos. Paulo Freire, entende esse viver coerente que, inclusive ele cobra dele mesmo, da seguinte forma:

A Pedagogia do oprimido é para mim um momento importante da minha vida em que ela, a Pedagogia, expressa um certo instante, exigindo, ao mes- mo tem, de mim, a coerência necessária como nela dito. Entre, as responsabilidades que, para mim, o escrever propõe, para não dizer impõe, há uma que sempre assumo. A de, já vivendo enquanto escrevo a coerência entre o escrevendo-se e o dito, o feito, o fazendo-se, intensificar a necessidade desta coerência ao longo da existência. A coerência, porém não é imobilizante. Posso no processo de agir-pensar, falar-escrever, mudar de posição. Minha coerência assim, tão necessária quanto antes, se faz como novos parâmetros. (FREIRE, 1997).

De acordo com Soares (2008), este é o caráter da coerência radical que representa uma exigência fundamental para a luta da libertação, coerência que se faz e refaz durante a própria luta ao que nela se manifesta, nas próprias palavras de Freire, da seguinte forma:

Sem preocupações puristas, os revolucionários devem, contudo, exigir de si mesmos uma radical coerência. A coerência entre seu discurso e sua prática para que não sejam uns ao falar, outros ao agir. Como homens e mulheres, podem equivocar-se e mesmo errar; o que não podem é, num momento, verbalizar a opção revolucionária e noutro, ter uma prática pequeno-burguesa (FREIRE, 2001).

Portanto, essa forma de se colocar no mundo, coerente, de maneira nenhuma, implica em fugir da realidade alienando-se como afirmam os críticos da espiritualidade, especialmente quando ela passa a ser apresentada como parte integrante do processo educativo, pois como vimos, somente a educação não permite ao homem se colocar como homem novo em libertação, pois essa tarefa depende de uma força, experimentada pelo homem, de dentro para fora que impulsiona o ser humano a redescobrir sua vocação ontológica de ser mais, libertar-se a si e os outros na radicalidade coerente provocada pela prática da liberdade que humaniza.

\section{CONSIDERAÇÕES FINAIS}

Nos propusemos investigar a possibilidade da relação entre a educação e a espiritualidade na formação do homem de modo que este, em vez de alienar-se, obtivesse a condição de ser mais e estar no mun- 
do de forma coerente, isto quer dizer, consciente de todas as problemáticas e formas opressoras do mundo que the cerca e que de forma intencional lhes oprime. Neste sentido, vimos que embora o discurso tecno-cientifico tenha prometido uma era de desenvolvimento social capaz de revolucionar para melhor a vida do homem, na verdade, estamos experimentando já algum tempo aquilo que Bauman (2004), chama de sociedade líquida, ou seja, tudo aquilo que a suposta ciência prometeu favorecer no desenvolvimento humano tomou um caminho oposto: nossas estruturas principais de relacionamento tornaram-se líquidas, frágeis.

Essa fragilidade forjou uma sociedade superficial e vazia, por exemplo, segundo a organização mundial da saúde (OMS) a taxa de mortalidade mundial aponta um padrão para doenças psíquicas: depressão, pânico, medo do outro, fobias, esquizofrenia, umas das maiores causas dessas doenças tem origem no estilo de vida das chamadas sociedades "modernas" totalmente doutrinadas pelo modelo trabalhar-consumir-ostentar-exibir poder. Por causa desse modelo que fere as bases do viver humano a espiritualidade aparece como alternativa de estabilização nos desencontros que provocam estas crises psíquicas que geram isolamento, violência, depressão, medo e alienação.

A espiritualidade como vimos aqui nada tem a ver com alienação ou algum tipo de romantismo espiri- tual que desmerece as realidades do mundo social em que vivemos inseridos. Nos propomos aqui investigar a espiritualidade como categoria pedagógica. Essa proposta confere um novo sentido a espiritualidade. Dessa forma, a espiritualidade não se opõe a educação enquanto ciência, assim sendo, caminhamos no sentido de que a educação somente não dá conta de proporcionar uma experiência de dentro para fora no homem capaz de inicia-lo no processo de sentir-se homem liberto, libertando o outro.

Vimos que para a espiritualidade assumir uma parceria com a educação no processo de formação humana é preciso envolver-se com um modelo de educação que proponha a problematização do cotidiano do homem, neste caso, resolvemos investigar a educação do ponto de vista do pensamento pedagógico de Paulo Freire. Uma pedagogia que problematiza o cotidiano para tornar o homem consciente de sua realidade opressora que não lhe permite viver a totalidade do potencial que a vida oferece.

Finalmente, investigamos a Pedagogia de Paulo Freire, seus aspectos libertadores que reconhecemos ter origem, além do pensamentos de Marx, também se origina na própria formação de Paulo Freire, formação para a vida que aponta a presença de um modelo de espiritualidade: não alienante, problematizadora, categoria pedagógica que problematiza o cotidiano, através da conscientização que humaniza o homem permitindo vive-lo a totalidade do bem viver. 


\section{REFERÊNCIAS}

BAUMAN, Z. Amor líquido. Sobre a fragilidade dos laços humanos. Rio de Janeiro: Zahar, 2004.

BOFF, Leonardo. Espiritualidade: um caminho de transformação. Rio de Janeiro: Sextante, 2001.

CEBs, Texto Base-CEBs: Espiritualidade libertadora. Diocese de Itabira. - Secretariado 11. Intereclesial das CEBs, Ipatinga: O Lutador, 2004.

FREIRE, Paulo. Conscientização: teoria e prática da libertação: uma introdução ao pensamento de Paulo Freire. São Paulo: Centauro, 2001.

Educação como prática de liberdade. Rio de Janeiro: Paz e Terra, 2006.

Ação cultural para Liberdade. Rio de Janeiro: Paz e Terra, 2001.

Pedagogia da Esperança. Rio de Janeiro: Paz e terra, 1997.

Pedagogia do Oprimido. Rio de Janeiro: Paz e Terra, 2005.

Pedagogia da autonomia: saberes necessários à prática educativa. São Paulo: Paz e Terra, 1996b.

O Papel da Educação na Humanização. Revista Paz e terra, Ano IV, no 9, Outubro, 1969.

GADOTTI, Moacir. A voz do biógrafo brasileiro: a prática à altura do sonho. In: Gadotti, Moacir. Paulo Freire: uma bibliografia. São Paulo: Cortez: Instituto Paulo Freire; Brasília, DF: UNESCO, 1996.

Paulo Freire. Uma bibliografia. São Paulo: Cortez Editora / Instituto Paulo Freire, 1996.
JUNQUEIRA \& SANTIAGO. R. A. O processo de escolarização do ensino religioso no Brasil. Petrópolis: Vozes, 2002.

MENDONÇA, Nelino Azevedo de. Pedagogia da Humanização - A pedagogia humanista de Paulo Freire. São Paulo: Paulus, 2008.

OLIVEIRA, P. C., \& Carvalho, P. d. (Agosto de 2007). A intencionalidade da consciência no processo educativo segundo Paulo Freire. Disponível em Scielo: http://www.scielo.br/ scielo.php? script =sci_arttext \&pid=s0103 $863 \times 2007000200006 \&$ Ing $=\overline{e n} \& n r m=i s s o$. Paulo: Paulus, 2008 .

PEÑALONZO, Jacinto Ordóñez. O Corte Epistemológico de Paulo Freire. IN: GADOTTI, Moacir. Paulo Freire. Uma Biobibliografia. São Paulo: Cortez Editora / Instituto Paulo Freire, 1996.

PARK, Peter. O amor na pedagogia de Paulo Freire. In FREI$\mathrm{RE}$, Ana Maria Araújo (Org.). A pedagogia da libertação em Paulo Freire. São Paulo: UNESP, 2001.

QUEIROZ, Carlos. Em busca da espiritualidade: o mercado da fé e o evangelho da graça. Viçosa/MG: Editora Ultimato, 2013.

SUNG, Jung Mo. Um caminho espiritual para a felicidade. Petropolis/RJ: Vozes, 2007.

Educar para reencantar a vida. Petrópolis/ RJ: Vozes, 2006.

SOARES, Adriana. Espiritualidade e educação para a liberdade. O opressor hospedado no oprimido de Paulo Freire e a teoria do desejo mimético de René Girard. Universidade Metodista de São Paulo. Faculdade de Filosofia e Ciências da Religião. Programa de Pós-graduação em Ciências da Religião. (Dissertação de mestrado), São Paulo: 2008. 